\title{
Case-based simulation scenarios in cardiology
}

This article was published in the following Dove Press journal:

Advances in Medical Education and Practice

\section{Mohsin Faysal Butt \\ Kabir Matwala ${ }^{2}$ \\ Rakin Rownak Choudhury \\ 'Barts and The London School of Medicine and Dentistry, Queen Mary University of London, London EI 2AT, UK; ' ${ }^{2}$ Department of Medicine, Imperial College London, London SW7 2AZ, UK}

Correspondence: Mohsin Faysal Butt Barts and The London School of Medicine and Dentistry, Queen Mary University of London, London EI 2AT, UK Email mohsinfaysalbutt@doctors.org.uk

\section{Dear editor}

We read with interest the study by Bilello et al, ${ }^{1}$ which assessed the utility of a cardiac case-based simulation scenario to investigate the physical examination performance of fourth-year medical students. As medical students, mannequins have granted us useful practical skills, but we recognize that they do not command the same feeling of dread nor the adrenaline surge that comes with managing a real-life cardiac arrest. This is a unique study design, and we respect the authors' description of its limitations, but for the educator who wishes to utilize mannequins in a similar investigation, we propose slight alterations to the study protocol.

Firstly, in order to increase the study's authenticity, we recommend mannequins to be used in conjunction with a simulated patient (SP), that is, lay persons or actors who adopt and adapt to a given patient scenario. ${ }^{2}$ In this scenario, an emergency physician provided the voice-over for the mannequin, but we would recommend an SP be present in the room, provide a voice-over for the mannequin and agree to being examined upon - except, of course, for cardiopulmonary resuscitation. From our experience, communication with an SP goes some way to affording genuineness to mannequins, allowing students to approach the situation more seriously and honestly.

Secondly, although assessing outcomes in relation to how well students perform focused physical examination components is valid, we feel it is important for future studies to assess outcomes respecting the universally recognized $\mathrm{ABCDE}$ assessment, which is intended as a rapid bedside assessment of a critically ill patient. ${ }^{3}$ This would require students to assess domains such as airway patency and hypoxia management, in order of priority, which together would make the scenario a more accurate reflection of a true cardiac arrest.

Thirdly, before commencing the study, it would have been interesting for the authors to have measured students' confidence levels, which could have unearthed a correlation between confidence levels and outcomes in cardiac arrest management. Overconfidence amongst physicians has long been considered a source of diagnostic error and poor patient management, ${ }^{4}$ and it would have been worthwhile to discern whether this phenomenon existed amongst medical students.

We agree with the study's findings regarding the need for a "call for improved technology to increase authenticity of simulators," but this must not detract us from another serious conclusion of the investigation that fourth-year medical students are, 
very worryingly, potentially not performing an adequate assessment of the cardiac arrest patient. This calls for more SP-based teaching - employing our aforementioned recommendations - in the management of cardiac arrest, which should be a fundamental skill in the House Officer's armory. Given that medical students are potentially not being adequately taught how to manage a cardiac arrest situation, the onus should also be on hospitals to commission more teaching on this subject to their newly appointed House Officers.

\section{Disclosure}

The authors report no conflicts of interest in this communication.

\section{References}

1. Bilello LA, Dubosh NM, Lewis JJ, Hall MM, Fisher J, Ullman EA. Fourth-year medical students do not perform a focused physical examination during a case-based simulation scenario. Adv Med Educ Pract. 2018;9:583-588.

2. Butt MF. Simulated patients uncovered. Clin Teach. 2018;15(1): $81-82$.

3. Thim T, Krarup NH, Grove EL, Rohde CV, Løfgren B. Initial assessment and treatment with the Airway, Breathing, Circulation, Disability, Exposure (ABCDE) approach. Int J Gen Med. 2012;5:117-121.

4. Berner ES, Graber ML. Overconfidence as a cause of diagnostic error in medicine. Am J Med. 2008;121(5 Suppl):S2-S23. 


\section{Authors' reply \\ Leslie A Bilello' \\ Nicole M Dubosh' \\ Jason J Lewis' \\ Matthew M Hall' \\ Jonathan Fisher ${ }^{2}$ \\ Edward A Ullman'}

'Department of Emergency Medicine, Beth Israel Deaconess Medical Center, Boston, MA, USA; 'Department of Emergency Medicine, Maricopa Medical Center, Phoenix, AZ, USA

Correspondence: Leslie A Bilello

Department of Emergency Medicine, Beth Israel Deaconess Medical Center, One Deaconess Road, 2nd Floor, Boston, MA 02215, USA

Tel + I 6177542339

$\mathrm{Fax}+\mathrm{I} 6177542350$

Email Ibilello@bidmc.harvard.edu

\section{Dear editor}

We appreciate the Letter to the Editor from Butt et al regarding our study and recent publication entitled, "Fourth-year medical students do not perform a focused physical examination during a case-based simulation scenario." This study sought to assess the physical examination performance of medical students in the simulation laboratory during a high-acuity cardiac case that later evolved into a cardiac arrest.

We agree with the letter writers that increased emphasis must be placed and future resources spent on the teaching of physical examination skills, which is one of the primary conclusions of our study. As stated in our introduction, we feel that "physical examination skills represent one of the most important diagnostic tools we impart to new generations of medical students and trainees." We the authors of this paper, aspire to achieve this in our work as medical educators and emergency medicine attending physicians.

We understand the writers' interest in incorporating live standardized patients, but we would like to highlight the fact that our study provided a standardized experience within the simulation laboratory with the use of mannequins. For each assessment, we utilized the same high-acuity cardiac casebased scenario with a standardized timeline in a controlled simulation setting. We feel this provides the most uniform research setting as opposed to live standardized patients.

Additionally, the suggestion from Butt et al regarding involvement of live standardized patients was to assess learners' communication skills. The focus of our study was to evaluate their physical examination performance in an environment that is similar to the clinical setting, such as our high-acuity cardiac arrest scenario for an emergency medicine clerkship. Although we appreciate the importance of teaching and evaluating learners' communication skills, the students' ability to communicate with a patient is not the primary aim of this study.

We thank the writers for their interest in our research and look forward to future studies aimed at improving the medical student simulation experience.

\section{Disclosure}

The authors report no conflicts of interest in this communication.

\section{Reference}

1. Bilello LA, Dubosh NM, Lewis JJ, Hall MM, Fisher J, Ullman EA. Fourth-year medical students do not perform a focused physical examination during a case-based simulation scenario. Adv Med Educ Pract. 2018;9:583-588.

Dove Medical Press encourages responsible, free and frank academic debate. The content of the Advances in Medical Education and Practice 'letters to the editor' section does not necessarily represent the views of Dove Medical Press, its officers, agents, employees, related entities or the Advances in Medical Education and Practice editors. While all reasonable steps have been taken to confirm the content of each letter, Dove Medical Press accepts no liability in respect of the content of any letter, nor is it responsible for the content and accuracy of any letter to the editor.

\section{Publish your work in this journal}

Advances in Medical Education and Practice is an international, peerreviewed, open access journal that aims to present and publish research on Medical Education covering medical, dental, nursing and allied health care professional education. The journal covers undergraduate education, postgraduate training and continuing medical education including emerging trends and innovative models linking education, research, and health care services. The manuscript management system is completely online and includes a very quick and fair peer-review system. Visit http://www.dovepress.com/testimonials.php to read real quotes from published authors. 